\title{
RESENHA \\ OS HCTPS DO PONTO DE VISTA DE UM GESTOR DO MINISTÉRIO DA JUSTIÇA
}

\author{
Oliveira, Ana (2009)"'O Buraco Negro do Ser: Manicômio do Vazio" - A (Des)Estrutura \\ dos Hospitais de Custódia e Tratamento Psiquiátrico no Brasil. Dissertação de Mestrado. \\ Programa de Mestrado em Ciência Política. Centro Universitário UNIEURO. 164 pgs.
}

Martinho Braga Batista e Silva - Consultor da Área Técnica de Saúde no Sistema Penitenciário - Ministério da Saúde

A dissertação da psicóloga Ana Cristina Oliveira - da Coordenação de Reintegração Social e Ensino do Departamento Penitenciário Nacional, no Ministério da Justiça - é sobre a estrutura dos Hospitais de Custódia e Tratamento Psiquiátrico (HCTP) no Brasil.

Reunindo dados do Sistema Integrado de Informações Penitenciárias (INFOPEN), a autora revela que o HCTP nem sempre serve ao cumprimento de medidas de segurança (71\% dos internos nessa condição), nem sempre é superlotado como outros estabelecimentos penais (menos da metade dos HCTPs) e nem sempre mantém os internos confinados por décadas ou por toda a vida, embora haja relatos dessa situação (permanência média de 4 anos).

Apesar dos dados apontarem para 3.953 internos nos HCTP em junho de 2008, os questionários respondidos pelos diretores dos 25 es- tabelecimentos estimam um número de 4.667, sendo que, proporcionalmente, há mais que o dobro de mulheres nos HCTPs do que em outros estabelecimentos penais (13\% contra $6 \%$ ).

A carência de recursos humanos é da seguinte ordem: além da falta de terapeutas ocupacionais, pedagogos, enfermeiros, assistentes sociais e dentistas em muitos HCTPs, em quase metade não há advogado e em um deles não há psiquiatra, embora sempre haja psicólogos. Metade dos exames de cessação de periculosidade é anual, sendo que em mais de $70 \%$ das vezes é realizado pela própria equipe do estabelecimento. Apenas $8 \%$ dos internos de HCTP freqüentam os Centros de Atenção Psicossocial ou Serviços Residenciais Terapêuticos, sendo que destes apenas 14\% recebe a bolsa do Programa De Volta para Casa.

Dado o volume de informações sobre os HCTP, essa dissertação de mestrado deve ser consultada por todos os envolvidos no atendimento às pessoas em medida de segurança. 